\title{
Evaluation of Home Based Junior Doctor Medical Simulator
}

\author{
Aidan Sliney \\ IMCLab \\ Dept of Computer Science \\ University College Cork \\ Ireland
}

ajs2@student.cs.ucc.ie

\author{
David Murphy \\ IMCLab \\ Dept of Computer Science \\ University College Cork \\ Ireland
}

d.murphy@cs.ucc.ie

\author{
David Phelan \\ IMCLab \\ Dept of Computer Science \\ University College Cork \\ Ireland
}

dtp1@student.cs.ucc.ie

\begin{abstract}
This paper presents initial research on a home based junior doctor medical simulator (JDoc) to improve the efficiency of junior doctor training within the restrictions imposed by the European Working Time Directive (EWTD). Our goal is to make complex theoretical medical knowledge more accessible. We developed a high fidelity test framework JDoc. Our objective is to understand the potential for medical simulation in junior doctor training. The paper outlines the design process and the construction of the simulator as well as a small scale post-test usability study amongst junior doctors from which we can assess the benefits of JDoc.
\end{abstract}

\section{Categories and Subject Descriptors}

I. 6. 8 [Simulation and Modelling]: Simulation Support Systems - Environments.

\section{K. 8 [Personal Computing]: Games}

J. 3 [Computer Applications]: Life and Medical Sciences Medical information systems

\section{General Terms}

Human Factors, Design, Performance,

\section{Keywords}

Medical Training, Computer Assisted Learning, Simulation, Serious Games, Support System,

\section{INTRODUCTION}

Research into and developments of medical simulators have seen significant enhancements in recent times. The use of HumanComputer Interaction (HCI) through such methods as affective computing to portray a mid-to-high level of fidelity is essential. The feeling of using a simulator or simply playing a game needs to be kept at a minimum in order to ensure that the users' experience of the interaction is as realistic as possible. Even if this is accomplished, the construction of a relevant mental model from a complex situation relies on the capacity of the learners to extract appropriate information from that situation [1]. To aid this,

Permission to make digital or hard copies of all or part of this work for personal or classroom use is granted without fee provided that copies are not made or distributed for profit or commercial advantage and that copies bear this notice and the full citation on the first page. To copy otherwise, to republish, to post on servers or to redistribute to lists, requires prior specific permission and/or a fee SIMUTOOLS 2008, March 03-07, Marseille, France

Copyright $\odot 2008$ ICST 978-963-9799-20-2
DOI 10.4108/ICST SIMUTOOLS2008.3077 learning content must be developed in such a manner that meaningful and sustainable learning effects with the learner can be created [2].

Conventional training methods comprised of texts and images provide restricted possibilities to describe a difficult context, whereas three dimensional views of complex situations can sometimes increase understanding giving simulated training an added advantage [3]. According to Thompson and Riding, animation facilitates learning when it presents fine-grained actions that static graphics do not present [4].

Usability also plays a key role in the fidelity of any medical simulation. Good usability practices leave the user to concentrate on the next action to take rather than how to take them. The possibility of immersion, which provides end users with the experience of being surrounded by the environment, has several opportunities for further research in psychology including object manipulation [5].

\section{WHAT IS THE PURPOSE OF THE JUNIOR SIMULATOR (JDOC)?}

The purpose of the JDoc is to familiarise junior doctors with the day-to-day stress of a hectic hospital. By simulating patients and creating scenarios using basic parameters provided by senior doctors, JDoc supplies junior doctors with valuable (virtual) experience, which otherwise would be unobtainable.

It both immerses the player in the believable world of a busy hospital at night and educates them as to the diagnostic procedures and medical criteria required while working on-call in a hospital ward.

As the need for doctors continuously increases, the ratio of junior doctors to senior doctors also increases. The junior doctor simulator addresses some of the associated problems. Instead of every senior doctor having to continuously teach while working with a trail of junior doctors, they will input interesting cases into JDoc. Using this method the senior doctor can concentrate more on his or her patients without compromising the quality of learning of the junior doctor. The simulator goal is expressed in terms of the effect that it will have on the player. JDoc establishes what the player will learn through prior research with many 
experienced doctors who have first-hand experience and knowledge of the relevant areas for junior doctor education.

Medical simulation has a key role to play in training all medical fields [6]. Medical simulation training programs have resulted in improved performance, shorter response time, and less deviation from practice standards than non-simulator training. Medical simulators increase trainee confidence, competence, and improve patient safety. Medical simulation training can also yield cost and process efficiencies.

The introduction of the European Working Time Directive (EWTD) has placed serious constraints upon medical education and has proven to be a major challenge for conventional training methods. Finding time for training has become an issue. The British Medical Journal [8] notes that "before the European Working Time Directive a trainee could expect to work over 30,000 hours between becoming a senior house officer and getting a consultant post. The Royal College of Surgeons calculates that this will now fall to 8000 hours." The issue medical staff are facing is that on-site training fits into the EWTD's classification of work, and is therefore included in the allotted hours. One potential solution is to further incorporate medical simulators and serious games into the medical curriculum.

The first and most important type of medical simulator is the single purpose simulator that is typically based in a hospital or medical training facility. An example would be a computer connected to relevant anatomy or a mannequin that responds to an action like the injecting of drugs. The Human Computer Interaction (HCI) and the usability practices of these simulators are minimal, with the use of mannequin's etc accounting for most of the user's actions. The second type of Medical simulator, the personal simulators, are the simulators that benefit from not been categorised by the EWTD as work. It is these types of simulators that require solid technological implementations through usability engineering and concise HCI methods to bring them to the level of satisfactory realism. These simulators suffer from the problem that they cannot operate in association with specialist instrumentation. It is not feasible to expect each doctor in training to own a standalone machine for each type of training module. This is one of the main goals of the current work.

\section{JDOC}

JDoc is an interactive, computer-based 1st -3rd person junior doctor simulator prototype. It is used to train and teach junior doctors. It is a simple, cheap and easy-to-use development model, where people are assisted by information technology [9]. It can be installed on any home computer that meets the minimal required specification. The users' actions are continuously logged for reviews and revision by either the user by comparison or by a senior doctor dependant on which situation is preferred. Interactive prototypes of specific fidelity enable a better understanding of end-users and their tasks, lead to a better collaboration and make it possible to produce better software faster [10]. Realistic prototypes help resolve detailed design decisions in layout, visual presentation, and component selection, as well as finding points in interaction design and interface behaviour [11].

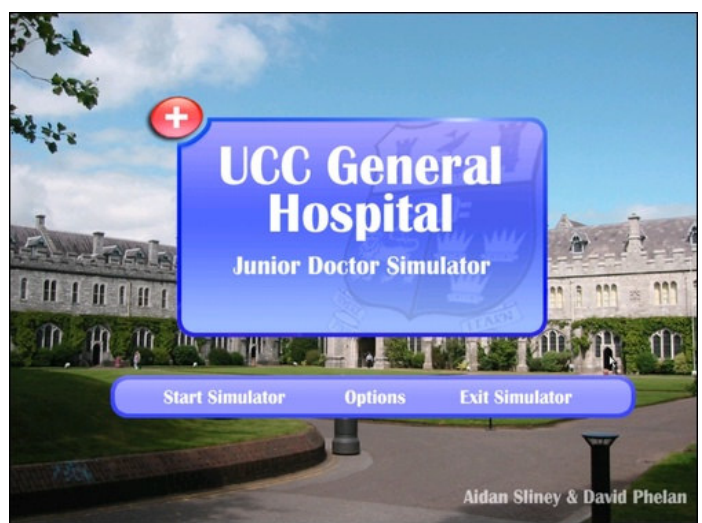

Figure 1. JDoc intro screen. From here they can begin the simulator, change the video/ audio setting or exit the simulator.

When the simulator is fully loaded, the user has to attempt to go from waiting on call to assessing the patient (Fig. 2.). When the user has finished using the simulator, all actions can be reviewed either by themselves or their supervisor in an individual txt file. Once a junior doctor logs onto JDoc they take control of a doctor model (an on call junior doctor). JDoc creates a file under the doctor's name in which all their actions will be documented.

The user must make their way to the hospital and then find and assess the patient. To accomplish this they must talk to other doctors and nurses (Non-Player Characters (NPCs)) ask questions and follow the correct protocol in assessing the patient. Each assessment and every reaction from the in-game doctors and nurses, and factors like ECGs, blood test results and patient history can differ as the senior doctors create a new scenario.
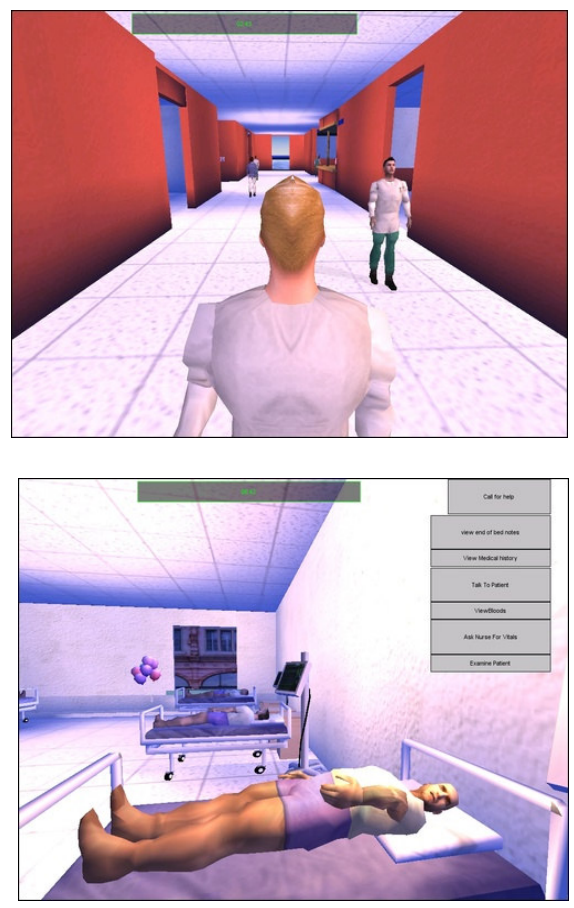

Figure 2. A selection of in game shots from JDoc. 


\section{THE OUTPUT}

For each user of JDoc an individual XML file is created. The file named after the users' log-in name records every movement and decision the user makes. Dependant on how JDoc is set up by the senior doctor this XML file can either contain the correct procedure for each step so the junior doctor can compare his/her own mistakes or it can be setup so only the senior doctor can assess each users' decision making skills and how well each user diagnosed the patient.

\section{USABILITY ASPECTS OF JDOC}

JDoc input devices are constrained to tactile (keyboard or mouse) and the output devices are constrained to visual (monitor) or aural (speakers). Any action the user wishes to carryout, be it simply unconstrained user movement or assessing a patient, is made by inputting their choice by keyboard (actions bound to a specific key) or by mouse (button click). The Predefined response to the users' choice is then relayed back through the monitor, through the speakers, or both. The first and most important usability aspect we looked at was the user's avatar itself. How would the user move the character? How would the user know he/she moved the character? Given our input devices constraint, we felt that the use of the arrow keys would be the easiest means of character movement. JDoc generally uses the 3rd person model but in any instance where the blind spot behind the model causes an obstruction the view changes to first person. This method still detracts from the fidelity of the game; however, user feedback has shown that it is adequate, especially when one considers the lack of sophisticated output devices

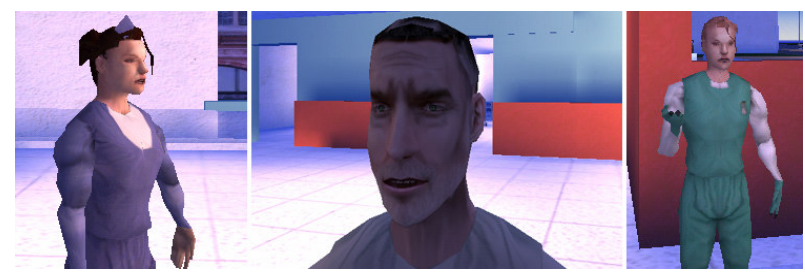

Figure 3. Here we see the view the user gets in first person while interacting with others.

Assessing the patient is another area in which good usability practices are essential to extend the fidelity of JDoc. This area differs from the first as it is dynamic. Again taking the available basic input devices, it was decided to use on-screen buttons and drop-down menus for the users to input their actions. This method is sufficient as it leaves the user thinking about what action to undertake rather than how to undertake it. Where responses become individual we use input boxes for the user to explain their actions. Good usability practice plays a vital role in JDoc. It is these practices that differentiate JDoc from a simple text based simulator. The use of good audio, camera positioning etc, creates an atmosphere inside JDoc that brings the users state of mind somewhat near the level needed in a real life scenario.

\section{HOW WAS JDOC BUILT?}

For the purposes of developing the JDoc prototype, the popular game engine, Torque Game Engine (TGE) from GarageGames was used. 3DS Max 8 was used for modeling. The game engine itself is coded in C++. These factors will all remain hidden from end users' of JDoc. Any new scenarios created by senior doctors shall be done through a simple Content Management System. Within this CMS there will be a series of simple questions with either tick boxes or text boxes that will edit the underlying code and will ultimately create new unique scenarios.

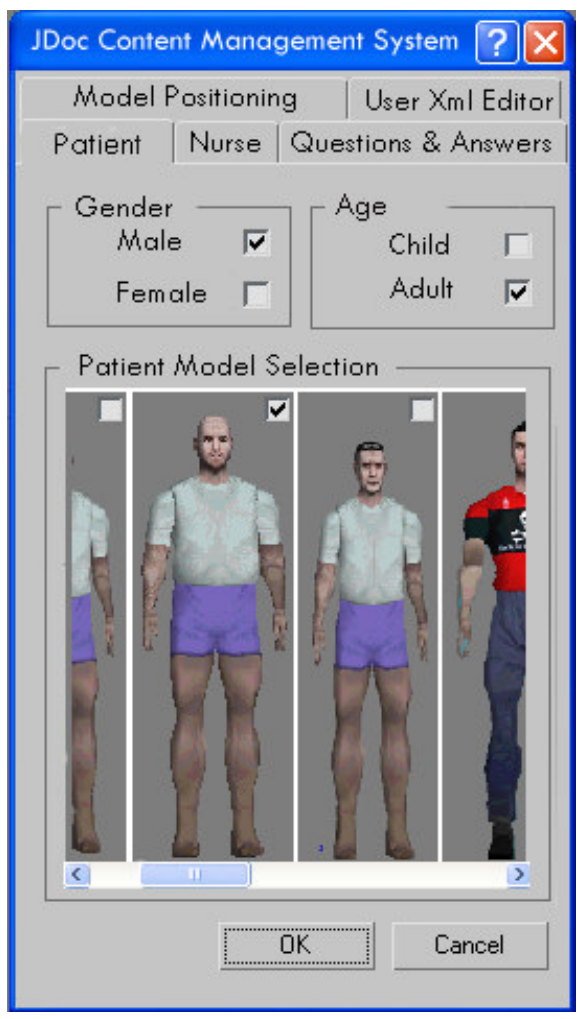

Figure 4. Using the JDoc CMS the senior Doctor is able to create new scenarios

\section{JDOC MECHANICS}

As JDoc is a framework each section workings is interchangeable. For example the virtual agents are built using 3ds Max, however any modeling program that is supported by the Torque Game Engine can be used. Other examples include Blender and Maya. Interactivity between the user and these virtual agents is achieved in two ways. The first is by placing a Trigger Box around the agent. When the user model enters this designated area a simple function with dynamic variables is called. It is the state of these simple variables that dictates how the virtual agent will respond. For example, the user enters the Trigger Box surrounding a senior doctor and the task is not completed correctly he will reprimand the user. Another example would be if you walked up to a nurse virtual agent and the variable storing "How New" you were to the 
simulator where ' 0 ' stood for beginner, ' 1 ' stood for returning user, if this variable stated " 0 " then the nurse would be triggered into following a path to help you find your patient whereas if the variable stated ' 1 ' then the nurse would give you very little help at all. The second form of interaction triggering is done by an 'On Collision call'. This occurs when the users bounding box collides with a virtual agent's bounding box. Every object within the simulator has a bounding box. This bounding box is given to each object within the modeling program it was created in. It simply represents the area within the object that is "solid". This is similar to the approach adopted with the 'Trigger Box' method. This method can be implemented by all virtual agents within Jdoc. The most common use of it would be with the agents that follow a path. If the user collides with these agents a function could be called where the agent gives out to the user for not looking where he was going. This then itself could trigger another variable that would contain that agents "happiness" towards the user. This "happiness" variable could then come into play, for example, if the user collides with this agent again.

Below is an example of a onEnterTrigger function.

function firstDoc::onEnterTrigger( \%this, \%trigger, \%obj )

\{

if(\%obj.getClassName() \$= "Player")

// if the player enter "firstDoc" trigger

\{

\$bot9.setActionThread("Point");

// the virtual agent animates point

schedule(3000,0,schedReturnToSwat);

// the virtual agents stops pointing

$\$$ talkedToFrstDoc $=1 ; / /$ memory variable

pic1.setVisible(true);

//the agents picture appears on screen

ServerConnection.setFirstPerson(\$firstPerson);

//camera view changes

bottomPrint(\%obj.client, "Hi you must be", 1, 1);

//text appears on the screen

\$bot9.setTransform(28.876 -281.253 $0.780628 \quad 0-1$

52.7121); // the agent turns

\}

\}

\section{GAME DESIGN TREE}

As our game design is intended to be dynamic we are going to use a tree structure to show its layout. A game tree is a directed graph whose nodes are positions in a game and whose edges are moves. The complete game tree for a game starts from the initial position and contains all possible moves from each position( Fig. 4.) This game design tree gives us the foundations and structure we need to visualize and understand the task ahead. After many cycles around our "Game Design Process", our game design tree slowly evolved and grew into more than just a design hierarchy. It became a very important game map that we constantly used to re assess our position and future actions. Our final Game Design
Tree shows how much our game design process affected and dynamically improved the final outcome. For ease of use our GDT can be split into three main sections

Section 1: From starting the simulator, to getting into the hospital.

Section 2: Getting from the hospital front doors to your patient.

Section 3: Assessing the patient.

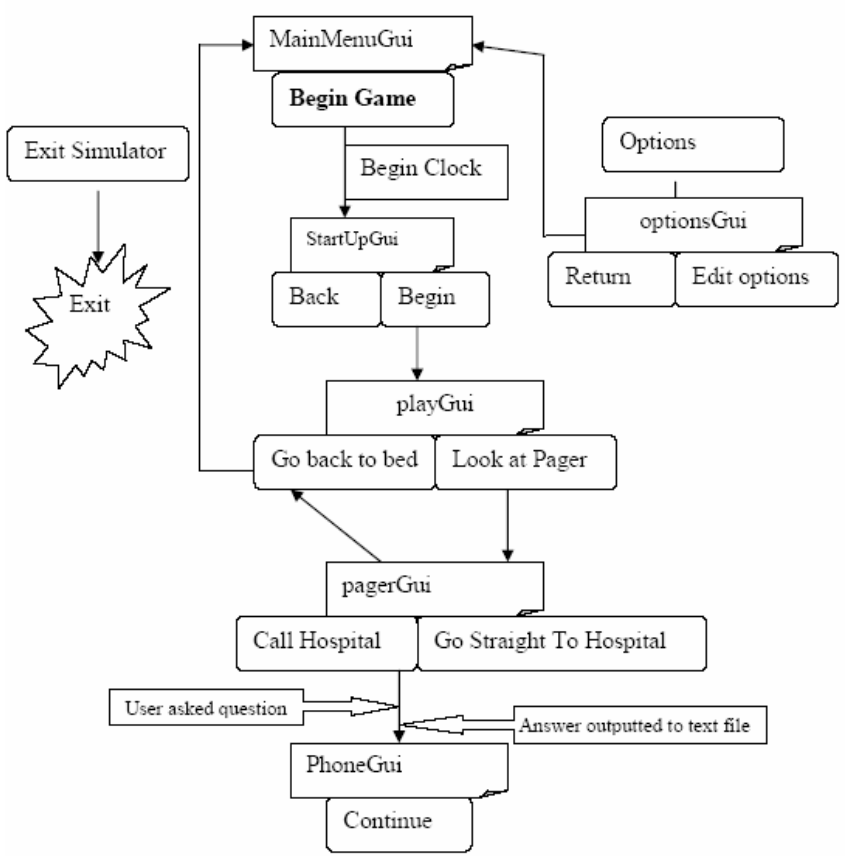

Figure 5. The game design tree of section 1

From here the user now has the simulator set to his/her preferences. An Xml file has been created under the Dr's name. If chosen to ring the hospital, the users predicted assessment has been saved to the Xml file. The user has the option to walk anywhere but should now make his/her way to the hospital as the time is ticking.

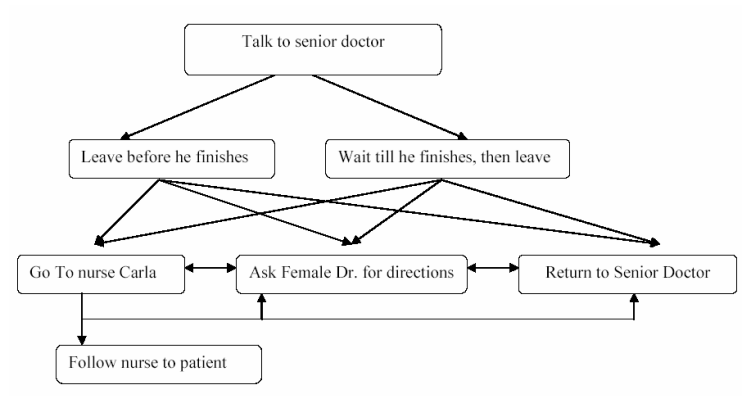

Figure 6. The game design tree of section 3 
The above game design tree was created dynamically as we developed the simulator. Each section is comprised of all the parts that make up the simulator.

\section{THE USABILITY TEST}

To evaluate our implemented framework from an end-users' perspective, a rapid usability test was performed. A test group of $n$ junior doctors, $(n=24)$, ranging from age 21-32 and mixed sex, from Cork University Hospital participated.

Table 1. The result from the junior doctors' survey

\begin{tabular}{|l|l|l|l|}
\hline Question & Yes & No & $\mathbf{5 0 \%}$ \\
\hline $\begin{array}{l}\text { Would the simulator benefit } \\
\text { junior doctors? }\end{array}$ & $100 \%$ & $0 \%$ & $0 \%$ \\
\hline $\begin{array}{l}\text { Do you think the data was } \\
\text { represented appropriately? }\end{array}$ & $90 \%$ & $0 \%$ & $10 \%$ \\
\hline $\begin{array}{l}\text { Did you think the sound } \\
\text { effects were realistic? }\end{array}$ & $100 \%$ & $0 \%$ & $0 \%$ \\
\hline $\begin{array}{l}\text { Do you think the model of } \\
\text { the hospital was realistic and } \\
\text { captured the feeling of a real } \\
\text { hospital? }\end{array}$ & $80 \%$ & $10 \%$ & $10 \%$ \\
\hline $\begin{array}{l}\text { Did you find the player } \\
\text { character easy to control? }\end{array}$ & $60 \%$ & $20 \%$ & $20 \%$ \\
\hline $\begin{array}{l}\text { Did you find the button } \\
\text { interface easy to follow? }\end{array}$ & $100 \%$ & $0 \%$ & $0 \%$ \\
\hline
\end{tabular}

To further understand some of our results we performed another rapid usability test this time on a control group, $\mathrm{m}=14$ "gamers" again of age 21-32 and mixed sex.

Table 2. The result from the gamers' survey

\begin{tabular}{|l|l|l|l|}
\hline Question & Yes & No & $\mathbf{5 0 \%}$ \\
\hline $\begin{array}{l}\text { Do you think the simulator } \\
\text { would benefit junior } \\
\text { doctors? }\end{array}$ & $70 \%$ & $0 \%$ & $30 \%$ \\
\hline $\begin{array}{l}\text { Do you think the data was } \\
\text { represented appropriately? }\end{array}$ & $70 \%$ & $0 \%$ & $30 \%$ \\
\hline $\begin{array}{l}\text { Did you think the sound } \\
\text { effects were realistic? }\end{array}$ & $100 \%$ & $0 \%$ & $0 \%$ \\
\hline $\begin{array}{l}\text { Do you think the model of } \\
\text { the hospital was realistic } \\
\text { and captured the feeling of } \\
\text { a real hospital? }\end{array}$ & $50 \%$ & $50 \%$ & $0 \%$ \\
\hline $\begin{array}{l}\text { Did you find the player } \\
\text { character easy to control? }\end{array}$ & $100 \%$ & $0 \%$ & $0 \%$ \\
\hline $\begin{array}{l}\text { Did you find the button } \\
\text { interface easy to follow and } \\
\text { use? }\end{array}$ & $100 \%$ & $0 \%$ & $0 \%$ \\
\hline
\end{tabular}

From these initial tests we are able to infer that the simulator will benefit junior doctors; the data and sound were acceptable, realism was acceptable for junior doctors but in the gaming world only adequate. The main point taken from these tests is the movement of the character. Gamers who have used these controls found them excellent therefore allowing us to infer, although some doctors struggled with these controls, with minimal experience, they would become more proficient. The simulator was also tested on a hallway group but the tests were deemed invalid as the users' within this group were distracted by medical terminology unknown to them.

The hi-realism prototyping had the advantage that end-users participated in,and were assessed studied in a realistic setting. [10]

\section{3D SIMULTION VS 2D SIMULATION}

Roger Schank, founder of vrtual learning company CognitiveArts put the use of simulation in context by saying, "Which would you rather your airplane pilot have -90 hours of the flight simulator, or 90 hours of book study?". He also makes that point that real world experience is essential but failing that simulation is the only other option: "I can give a child the best instruction money can buy in how to ride a bicycle. I can show her a step-by-step procedure for getting on the bike and pedaling it; I can show her films that demonstrate how one keeps one's balance while pedaling; I can inspire her with stories of bicycling daring. But unless the child gets on the bike, gets help when she falls off, and practices until she doesn't fall again, she's never going to learn how to ride."

\section{FUTURE WORKS}

Future work on the Junior Doctor Simulator has numerous possibilities. Many new scenarios could be built and new models and characters can be continuously

\section{SIMULATION IN MEDICINE}

Future work on the Junior Doctor Simulator has numerous possibilities. Many new scenarios could be built and new models and characters can be continuously added. The big forward step for this project would be to add a Content Management System (CMS) screen for the senior doctors to continuously edit and update the scenarios (Fig. 4.). Each new scenario built in each hospital can then be added to a database and then made accessible to any user of JDoc over the internet making the amount of scenarios potentially endless. Critical pedagogy Scenarios will also be built to expand teaching strategies and to prevent the scenarios from becoming static e.g. having actions return incorrect results and letting the user have of the option of flagging these inconsistencies. The data should adapt to individual needs and levels of expertise in order to enhance cognitive performance, the system will learn with the user [12].

\section{REFERENCES}

[1] R.K. Lowe, "Processing challenges pf understanding complex animated pictures", 12(2-3), 125-134, (1998) 
[2] M. Allen, "Michael Allen's Guide to e-Learning, Building Interactive, Fun, and Effective Learning Programs for Any Company” Hoboken: John Wiley \& Sons Inc. (2003)

[3] S. Guttormsen-Schar, and H. Kruegar, "Using new Learning Technologies with Multimedia. IEEE MultiMedia 7(3), 40$51(2000)$

[4] S. V. Thompson and R. J. Riding, The effect of animated diagrams on the understanding of a mathematical demonstration in 11- to -14-year-old pupils. British Journal of Educational Psychology, 60, 93-98. (1990)

[5] J.M. Loomis, J.J. Blascovich, and A.C Beall, "Immersive virtual environment technology as a basic research tool in psychology", Behaviour Research methods Instruments \& Computers 31(4), 557-564 (1999)

[6] J. Chikwe, A. C De Soiuza, and J.R. Pepper, British Medical Journa,l (2004)

[7] S. Calnan, "European Working Time Directive - Ireland Failing to Implement New Regulations" (2005)

[8] D. Hanly, "Report of the National Task Force on Medical Staffing" (2003).

[9] C. Stephanidis, and A. Savidis,. "Universal Access in the information Society Methods, Tools and Interaction Technologies." Universal Access in the Information Society 1(1), 40-55 (2001)
[10] T. Memmel, H. Reiterer, and A. Holzinger, "Agile methods and Visual Specification in Software Development" A Chance to Ensure Universal Access 454- 461 (2007)

[11] L.L Constantine, "Canonical Abstract Prototypes for Abstract Visual and Interaction Design In: Jorge, J.A., Jardim Nunes, N., Falcao e Cunha, J. (eds.)B DSV-IS 2003." LNCS, vol. 2844, Springer, Heidelberg (2003)

[12] A. Holzinger, G. Searls, and A. Nischelwitzer, "On some Aspects of Improving Mobile Applications for The Elderly" Universal Access in HCI. LNCS, vol. 4554, Springer, Heidelberg 923-932, (2007)

[13] Experience Builders LLC (2003). "A Comparison of Simulation-Based and Conventional Training Methods"

[14] A. J. Faria, Business Simulation Games: Current Usage Levels-An Update. Simulation and Gaming, Volume 29 number 3, pages 295-308.(1998).

[15] J. Wolfe, The Effectiveness of Business Games in Strategic Management Course Work. Simulation and Gaming, volume 28 number 4, pages 360-376. (1997).

[16] D. M. Lane, and T. Zhihua. "Effectiveness of Simulation Training on Transfer of Statistical Concepts". Journal of Educational Computing Research, volume 22, number 4, pages 383-396 (2000). 